\title{
Editorial
}

\section{Advances in Industrial and Environmental Microbiology}

\author{
Slawomir Ciesielski ${ }^{1, *(\mathbb{D})}$ and Ivone Vaz-Moreira ${ }^{2, *(\mathbb{D})}$ \\ 1 Department of Environmental Biotechnology, University of Warmia and Mazury in Olsztyn, Sloneczna 45G, \\ 10-709 Olsztyn, Poland \\ 2 CBQF-Centro de Biotecnologia e Química Fina-Laboratório Associado, Escola Superior de Biotecnologia, \\ Universidade Católica Portuguesa, Rua de Diogo Botelho 1327, 4169-005 Porto, Portugal \\ * Correspondence: slawomir.ciesielski@uwm.edu.pl (S.C.); ivmoreira@ucp.pt (I.V.-M.)
}

check for updates

Citation: Ciesielski, S.;

Vaz-Moreira, I. Advances in

Industrial and Environmental

Microbiology. Appl. Sci. 2021, 11 ,

9774. https://doi.org/10.3390/

app11209774

Received: 30 September 2021

Accepted: 14 October 2021

Published: 19 October 2021

Publisher's Note: MDPI stays neutral with regard to jurisdictional claims in published maps and institutional affiliations.

Copyright: (C) 2021 by the authors Licensee MDPI, Basel, Switzerland. This article is an open access article distributed under the terms and conditions of the Creative Commons Attribution (CC BY) license (https:// creativecommons.org/licenses/by/ $4.0 /)$.

\section{Introduction}

Understanding microorganisms in terms of their functionality, diversity, and interactions with other organisms is crucial for better understanding of our Biosphere. However, this can be difficult, not only because of their small size, but also because of their rapid evolution and tendency to create multispecies communities. The structures of microbial communities are closely associated with environmental conditions and therefore are likely to evolve in the context of global change [1]. Microbial communities can be divided into subcommunities, based on different attributes, such as abundance, functional type, and activity. They can differ in their environmental sensitivity, interaction, and distribution patterns [2].

The main impediment to a better understanding of the structure and function of microbial communities has been a lack of research tools that are sensitive enough. For decades, moreover, researchers have tried to cultivate microorganisms in laboratory conditions with only limited success. The rapid evolution of these organisms causes their physiological requirements to change faster than was expected, and growth conditions cannot be established for many of them. Therefore, methods based on analysis of nucleic acids recovered directly from environmental samples have become standard approaches for the characterization of microbial communities. In particular, next-generation DNA sequencing methods and in silico analyses have allowed researchers to address problems associated with unculturable microorganisms [3]. The metaomics approaches, including phylogenetic marker-based microbiome profiling, shotgun metagenomics, metatranscriptomics, metaproteomics, and metabolomics, have not only allowed identification of unculturable microorganisms but have also provided information about their physiological status.

Due to their ubiquity, microorganisms have developed innumerable substrate utilization mechanisms, which allow them to survive and evolve in even the most difficult environmental conditions. Their metabolic versatility means that microorganisms could be the source of various biochemicals, such as drugs, biopolymers, and enzymes. Additionally, this metabolic versatility makes microorganisms invaluable for environmental protection, especially in bioremediation, wastewater treatment, and conversion of biomass into energy.

This Special Issue on "Advances in Industrial and Environmental Microbiology" presents a collection of articles that focus on both applied and environmental microbiology, which are briefly summarized here for the convenience of the reader.

\section{Industrial Microbiology}

The potential and recent applications of xanthan gum biopolymer, with a particular focus on improving soil properties is reviewed by Mendonça et al. [4]. Xanthan gum is a polysaccharide formed by aerobic fermentation of sugar by Xanthomonas campestris. It is commonly used as a food additive because it can serve as a hydrocolloid rheology modifier. Soil treatment with xanthan gum has been shown to induce partial filling of soil voids and the generation of additional links between soil particles, which decreases the permeability 
coefficient of the soil and changes its mechanical properties. Via the bioclogging method, xanthan gum can be used to enable the filling of soil pores and the formation of a barrier that can increase the strength and cohesion and reduce the permeability coefficient of the soil. The authors conclude that these findings should be tested in practice to support the results obtained from laboratory experiments.

The treatment of wastewater in sequencing batch reactors with a high concentration of suspended solids from meat processing is the subject of a research article authored by Jachimowicz et al. [5]. The main aim of their study was to explore interrelationships between the aeration mode, microbial community composition, and the efficiency of removal of nitrogen, phosphorus, organic compounds, and total suspended solids. The authors show that intermittent aeration significantly increases denitrification and phosphorus removal efficiencies but leads to the decomposition of extracellular polymeric substances. In addition, they show that the microbial structure changes significantly over time. They report that, in mature granules during the period of stable treatment of meat-processing wastewater, an increased relative abundance of Arenimonas sp., Thauera sp., and Dokdonella sp. is typical. Additionally, they show that constant aeration favors the growth of microorganisms from the Rhodanobacteraceae, Rhodobacteraceae, and Xanthomonadaceae families, while intermittent aeration favors the growth of the Competibacteraceae family.

\section{Environmental Microbiology}

Recent advances in understanding of the role of microbial communities in subterranean ecosystems, namely their contribution to biogeochemical processes affecting the composition of the subterranean atmosphere and the availability of nutrients is reviewed by Martin-Pozas et al. [6]. These bacterial communities have been found to actively contribute to the uptake-fixation-production of $\mathrm{CO}_{2}, \mathrm{CH}_{4}$, and $\mathrm{NxOx}$ gases. In addition, the bacteria from these still poorly explored niches display potential to serve as producers of bioactive compounds with antibacterial, antifungal, or anticancer activities, as well as enzymes with biotechnological applications. Moreover, methanotrophs and heterotrophs in subterranean environments can interact and stimulate each other's growth, and their growth is associated with the production of bioactive compounds. The advent of massive sequencing technologies and the omics sciences have brought to bear important tools for continued exploration of the potential of biological processes in subterranean ecosystems.

Taking into consideration the origin and proportion of wastewater effluents (urban, hospital, livestock farms, or industrial), Rolbiecki et al. [7] do an analysis of the efficiency of wastewater treatment plants (WWTPs) in reducing the prevalence of antibiotic resistance genes (ARGs). They also examine the effect of the treated wastewater on the receiving water bodies (rivers). Their first conclusion is that the prevalence of ARGs in raw wastewater is affected by the origin of the sewage. For example, agricultural sewage containing animal waste is associated with a higher abundance of the sul2 gene, while hospital wastewater appears to be the main source of the sul1 gene. The authors also conclude that WWTPs are important sources of dissemination of ARGs to receiving water bodies. Metagenomic and metatranscriptomic analyses will be applied to these samples to increase knowledge about system dynamics, to develop effective strategies for managing risks, and to evaluate effects on human health.

In some natural ecosystems, invasion by exotic plants poses a threat to the equilibrium of the environment. For this reason, Cao et al. [8] studied the influence of Alternanthera philoxeroide (alligator weed) invasion on wetland organic matter accumulation and bacterial community changes. Samples were collected from two sediment depths $(0-15$ and $15-25 \mathrm{~cm}$ ) in invaded and normal habitats in two natural wetlands and two constructed wetlands. They observed that the contents of the light fractions of organic carbon and nitrogen were significantly higher in the constructed wetlands than in the natural wetlands, and the contents of the $\mathrm{C}$ and $\mathrm{N}$ fractions were also higher in the invaded areas than in the normal wetland habitats. The presence of the invasive weed also correlated with changes in the wetlands' microbiota. Although Proteobacteria, Bacteroidetes, Acidobacteria, 
and Chloroflexi were the dominant bacterial phyla in the wetlands, the abundance of Acidobacteria, Actinobacteria, and Gemmatimonadetes was significantly higher in invaded areas.

\section{Conclusions}

The scientific articles covered by this Special Issue show that the study of bacterial communities as a whole is essential for understanding the dynamics of both industrial and natural environments. The interactions between the different members of a bacterial community determine not only the structure but also the composition of the community. Additionally, the presented papers, although they approach different problems, show that rapid progress is possible thanks to modern research tools. In particular, the use of omics tools has become an important part of all fields of microbiological study.

Author Contributions: Conceptualization, S.C. and I.V.-M.; writing-original draft preparation, S.C. and I.V.-M.; writing-review and editing, S.C. and I.V.-M. All authors have read and agreed to the published version of the manuscript.

Funding: This research received no external funding.

Acknowledgments: I.V.-M. would like to thank the scientific collaboration under the FCT project $\mathrm{UIDB} / 50016 / 2020$.

Conflicts of Interest: The authors declare no conflict of interest.

\section{References}

1. Gutknecht, J.L.M.; Field, C.B.; Balser, T.C. Microbial communities and their responses to simulated global change fluctuate greatly over multiple years. Glob. Chang. Biol. 2012, 18, 2256-2269. [CrossRef]

2. Liu, J.; Meng, Z.; Liu, X.; Zhang, X.-H. Microbial assembly, interaction, functioning, activity and diversification: A review derived from community compositional data. Mar. Life Sci. Technol. 2019, 1, 112-128. [CrossRef]

3. Malla, M.A.; Dubey, A.; Yadav, S.; Kumar, A.; Hashem, A.; Abd_Allah, E.F. Understanding and designing the strategies for the microbe-mediated remediation of environmental contaminants using omics approaches. Front. Microbiol. 2018, 9, 1132. [CrossRef] [PubMed]

4. Mendonça, A.; Morais, P.V.; Pires, A.C.; Chung, A.P.; Oliveira, P.V. A Review on the Importance of Microbial Biopolymers Such as Xanthan Gum to Improve Soil Properties. Appl. Sci. 2021, 11, 170. [CrossRef]

5. Jachimowicz, P.; Cydzik-Kwiatkowska, A.; Szklarz, P. Effect of Aeration Mode on Microbial Structure and Efficiency of Treatment of TSS-Rich Wastewater from Meat Processing. Appl. Sci. 2020, 10, 7414. [CrossRef]

6. Martin-Pozas, T.; Gonzalez-Pimentel, J.L.; Jurado, V.; Cuezva, S.; Dominguez-Moñino, I.; Fernandez-Cortes, A.; Cañaveras, J.C.; Sanchez-Moral, S.; Saiz-Jimenez, C. Microbial Activity in Subterranean Ecosystems: Recent Advances. Appl. Sci. 2020, 10, 8130. [CrossRef]

7. Rolbiecki, D.; Harnisz, M.; Korzeniewska, E.; Jałowiecki, Ł.; Płaza, G. Occurrence of fluoroquinolones and sulfonamides resistance genes in wastewater and sludge at different stages of wastewater treatment: A preliminary case study. Appl. Sci. 2020, 10, 5816. [CrossRef]

8. Cao, Q.; Zhang, H.; Ma, W.; Wang, R.; Liu, J. Composition characteristics of organic matter and bacterial communities under the Alternanthera philoxeroide invasion in wetlands. Appl. Sci. 2020, 10, 5571. [CrossRef] 